\title{
Lingua em museu: institucionalização de um nós no recobrimento de um resto histórico
}

\author{
Language in museum: institutionalization of an us in a covering of a \\ historical leftover \\ Claudia Castellanos Pfeiffer \\ Labeurb/Nudecri, Universidade Estadual de Campinas, Campinas, SP, Brasil
}

Resumo: Trata-se de um ensaio analítico que, a partir da Análise de Discurso, na sua relação com a História das Ideias Linguísticas, procura compreender parte do processo de institucionalização da língua portuguesa no Brasil tendo como arquivo a página eletrônica que acolhe o discurso institucional do Museu da Língua Portuguesa, que, por sua vez, se constitui em um discurso sobre (MARIANI, 1998) a língua portuguesa.

Palavras-chave: Museu da Língua Portuguesa. Institucionalização. Política pública.

Abstract: This is an analytical essay that, from the Analysis of Discourse, in its relation with the History of Linguistic Ideas, seeks to understand part of the process of institutionalization of the Portuguese language in Brazil, having as a file the electronic page that houses the institutional discourse of the Museu da Língua Portuguesa that, in turn, is constituted in a discourse about (MARIANI, 1998) the Portuguese language.

Keywords: Museu da Língua Portuguesa. Institutionalization. Public policy. 


\section{Introdução}

O que significa a instalação pública de um projeto de governo em nível estadual que promove a edificação de um Museu da Língua Portuguesa? Tomar esse espaço material (simbólico, político, histórico e físico) do ponto de vista discursivo e por uma história das ideias linguísticas (ORLANDI, 2001) nos faz colocar em relação o funcionamento:

- da língua;

Claudia

- das políticas públicas;

Castellanos

Pfeiffer

- dos discursos especializados (pensando aí o entremeio entre discurso científico - um discurso de um saber sobre a língua -, um discurso midiático/tecnológico e um discurso estético/artístico).

Dito de outro modo, trata-se de colocar em relação o Estado, o Conhecimento e a Sociedade (ORLANDI, 2001).

Tomamos essa relação enquanto tensa e contraditória e a pensamos como parte estruturante da produção do ordinário de sentido (PÊCHEUX, 1981). Mais especificamente, quando estamos pousando nosso olhar para uma escuta social (política) (PÊCHEUX/THOMAS HERBERT, 1966) de um espaço que tem a língua como objeto de exposição, observamos essa relação enquanto uma direção determinada de sentidos que afeta o imaginário do brasileiro na/da língua portuguesa, com toda a sua espessura semântica (PÊCHEUX, 1975), que é também afetada por uma construção histórica e política (ideológica) de um saber sobre a língua.

\section{O museu na trama de análises discursivas}

O que vem se compreendendo discursivamente é que o Museu da Língua Portuguesa estabiliza um processo de significação, na tensão entre a unidade imaginária e a diversidade concreta (ORLANDI, 2001), por meio de um princípio ético que sustenta uma política (linguística) que tem como valor estruturante a unidade (ORLANDI, 1998a) que é trabalhada no contraposto da variação. Quanto a isso, vemos com Silva Sobrinho (2011, p. 87) que

Na discursividade do museu, trata-se de uma história particular de variações produzidas, de um lado, pelo contato da língua do colonizador português com as línguas indígenas, africanas e de imigração e, de outro, pelo surgimento das novas tecnologias de 
comunicação e informação e pelo crescimento da urbanização e da escolarização. Na história da língua contada pelo museu, essas novas condições de produção teriam ocasionado apenas variações na Língua Portuguesa transferida para o Brasil. Falamos a mesma língua do colonizador, com variações, diz essa história. Apaga-se, desse modo, o processo de descolonização linguística, lembrando que, discursivamente, o que é apagado continua produzindo efeitos.

A língua é compartimentada em suas variantes a partir de uma unidade. Como significa essa unidade e como significa sua variação é uma questão de análise. Seus efeitos apontam para um apagamento que

Língua em museu acompanha o processo de gramatização brasileiro. Retomamos Orlandi (1998b) quando afirma, pensando sobre o discurso da globalização, que um de seus efeitos é o silenciamento da

[...] relação complexa entre universalização e historicização em seu movimento contínuo na busca de uma relação regrada entre Unidade e Diversidade. Porque o efeito mais importante do discurso da globalização é o de se substituir o universal e reduzir as diferenças (do nível da constituição, da historicidade) a variedades locais (do nível da formulação). Isto apaga o que é da ordem do jurídico, da forma do político, e, consequentemente, aquilo que poderia provocar uma 'mexida' no sentido e no sujeito. (ORLANDI, 1998b, p. 80).

Para nós, o efeito do Museu é da mesma ordem quando pratica um discurso sustentado em uma ética que tem como valor a unidade desdobrada em variações e em contiguidades linguísticas que apontam para uma linearidade cronológica e uma tecnicidade descritiva que retira as línguas da história no sentido que lhe damos na Análise de Discurso (AD): historicidade ${ }^{1}$. E aí a língua portuguesa encontra-se ao lado de língua-mãe, línguas-irmãs, línguas estrangeiras. E, ao lado, em uma contiguidade estéril. Como nos mostra Silva Sobrinho, em sua análise sobre os nomes da língua do Brasil no Museu da Língua Portuguesa:

1 Concebida como sendo o trabalho discursivo que organiza sentidos conflitantes para as relações de poder presentes em uma formação social (INDURSKY, 1998). 
Pode-se afirmar que a designação de nossa língua nacional como Língua Portuguesa [...] está sujeita a ambiguidades, equívocos, contradições. Há um jogo na referencialidade desse nome: ele refere tanto a unidade linguística do Brasil quanto a unidade da língua da colonização. Ele refere a unidade imaginária da língua e do Estado brasileiro e, ao mesmo tempo, a unidade imaginária da lusofonia, que apaga as descontinuidades na história da Língua Portuguesa, descontinuidades

Claudia

Castellanos

Pfeiffer que produziram diferentes 'sítios de interpretação'. (Orlandi, 1990). (SILVA SOBRINHO, 2009, p. 393).

O que estamos salientando é um apagamento histórico que se dá em torno da fixidez de um Brasil monolíngue. Quanto a isso, lembramo-nos de Orlandi, quando afirma que

Não há país que não seja multilíngue. Dito de outro modo: não há país monolíngue. Não há Estado que, embora em sua institucionalidade apresente sua ou suas línguas oficiais, nacionais, não se faça no contato com múltiplas línguas. E a língua não é una, não é uma, não é pura. É feita de falhas, de mudanças, de contatos variados. As línguas mudam, entram em contato entre si, desaparecem, se criam. Estão sempre incompletas, em movimento, assim como as identidades são um movimento na história. Não há Nação que não produza uma riqueza imensa na relação de sua(s) língua(s) e sua(s) cultura(s). Relação complexa, portanto, que não existe em linha reta, não é exata e demanda que se pense a história, a sociedade, e a política. (ORLANDI, 2012, p. 6).

Esse apagamento - fundador de um país monolíngue - provoca-nos uma inquietude ainda maior que procura compreender, como o fez Cervo (2012), o funcionamento de uma língua designada "portuguesa", a que é atribuída a dimensão de patrimônio - imaterial -, fazendo jus a ser objeto de exposição. Nessa inquietude, tira-se da evidência a naturalidade de se fazer de uma língua um patrimônio. Quanto a isso, acompanhamos a reflexão da autora sobre a questão central de sua pesquisa - língua patrimônio

O que temos designado como língua patrimônio significa uma possibilidade outra de versão de memórias e histórias a serem 
contadas sobre nós mesmos, portanto, um modo de interpretarmos a nossa própria significação sócio-histórica na/da/pela língua. Em termos de uma aproximação inicial entre os dois conceitos, língua e patrimônio, nós diríamos que estamos trabalhando no limiar de uma língua tomada como 'nossa', muito embora a questão do pertencimento nos alerte para o fato de que esse nós pode não ser necessariamente inclusivo, ainda que funcione por sentidos de universalização. Há língua, há línguas, há a língua do outro, há a minha língua, há a nossa língua. Há o saber sobre a língua. E há, como afirma Scherer (2003), a língua da memória e a memória da língua. Como mensurarmos o que é a língua patrimônio diante dessa filiação a uma memória sempre heterogênea? (CERVO, 2012, p. 17).

Língua em museu

Sabemos bem que toda universalização implica apagamentos. Mas sabemos também que mesmo que não se diga sobre ela, mesmo que ela não tenha espaço de ser narrada, a historicização também trabalha seus sentidos na língua: lugares de resistência, lugares de inscrição dos sujeitos. É essa tensão entre universalização e historicização que estrutura o processo de gramatização (AUROUX, 1992) da língua portuguesa no Brasil (ORLANDI, 2001).

Apesar da tensão, há uma sobredeterminação da universalização. Nesse sentido, é preciso observar o que está na base da significação de patrimônio, tão bem compreendido por Cervo (2012, p. 23):

\footnotetext{
Se, antes de tratarmos do conceito propriamente, pudéssemos resumi-lo mediante todo o nosso percurso de estudo e de levantamento de referencial bibliográfico, diríamos que o patrimônio se constitui da necessidade que temos de dar lugar e representação à memória, contra o que seria a maior transgressão neste caso: o esquecimento.
}

O que é preciso não poder esquecer? O que é preciso se dar na ordem da universalização e da completude? Inquietude que nos move e nos faz lembrar a noção cara à $\mathrm{AD}$ de arquivo e tão bem trabalhada por Romão (2011) quando toma para si uma análise provocativa sobre o Museu da Língua Portuguesa colocando em relação a linguística, a análise de discurso e a tradição documental das disciplinas da informação. Diz-nos a autora 
0 arquivo não comporta tudo, tampouco está em sua ordem o fato de tudo nele poder guardar; dessa maneira, há ainda uma condição estrutural de todo arquivamento que precisa ser levada em consideração, a não neutralidade do que é retido como efeito de verdade. (ROMÃO, 2011, p. 103).

E, ao mesmo tempo, como nos mostra a autora, conversando produtivamente com Pêcheux,

Claudia

Castellanos

Pfeiffer
O arquivo é sempre desdobrável, nascido e desfeito a partir da fecundação e abrigo de várias vozes, processo esse marcado pelo processo histórico de 'divisão social do trabalho de leitura' (Pêcheux, 1982, p. 58), que o autor acredita inscrever-se 'numa relação de dominação política: a alguns, o direito de produzir leituras originais, logo 'interpretações', constituindo, ao mesmo tempo, atos políticos (sustentando ou afrontando o poder local); a outros, a tarefa subalterna de preparar e de sustentar, pelos gestos anônimos do tratamento 'literal' dos documentos, as ditas 'interpretações'. (ROMÃo, 2011, p. 108).

Romão (2011) nos mostra a tensão entre um trabalho de interpretação que antecede a apresentação do arquivo montado nos espaços institucionais de poder, como os museus, bibliotecas, centros de memória, e o devir, para os furos. Não há ritual sem falhas, já nos ensinou nosso mestre.

E nas brechas, há também resistências, que podem ser observadas nas exposições já analisadas por trabalhos como o de Romão (2011), de Silva Sobrinho $(2009,2011)$ e de Cervo (2012) e que nos mostram, conforme Pêcheux, que

O discurso não é um aerólito miraculoso, independente das redes de memória e dos trajetos sociais nos quais ele irrompe [...] só por sua existência, todo discurso marca a possibilidade de uma desestruturação-reestruturação dessas redes e trajetos: todo discurso é o índice potencial de uma agitação nas filiações sócio-históricas de identificação, na medida em que ele constitui ao mesmo tempo um efeito dessas filiações e um trabalho (mais ou menos consciente, deliberado, construído ou não, mas de todo modo atravessado pelas determinações inconscientes) de deslocamento no seu espaço. (PÊCHEUX, 1997, p. 56). 
É justo sobre isso que nos fala Silva Sobrinho:

A colonização linguística foi, como assinala Mariani (2004), um dos elementos centrais do projeto colonizador de Portugal no Brasil. O governo português impôs sua língua, com sua memória, aos povos conquistados do Brasil como forma de manter a dominação.

Não se pode deixar de observar, porém, que a colonização linguística não foi um ritual sem falhas. [...] posta em funcionamento sob diferentes condições de produção, a Língua Portuguesa trazida pelo colonizador se reterritorializou instaurando novos modos de significar. Produziu-se, à época da colonização, Língua em uma clivagem na história da Língua Portuguesa (Orlandi, 1993). (SILVA SOBRINHO, 2009, p. 392-393).

No entremeio a essa clivagem, na necessidade constante de esquecer que a língua se reterritorializa porque é parte constitutiva dos modos de subjetivação do sujeito em sua inscrição na história, no político, vão se construindo instrumentos que sistematizam, organizam, dão visibilidade a uma língua imaginária (ORLANDI, 1992). É essa língua, apesar dos furos e brechas, que é exposta no Museu.

\section{O museu como instrumento}

Tomaremos, em nossa análise, o Museu da Língua Portuguesa como um instrumento linguístico (AUROUX, 1992) em sua dimensão discursiva, que o compreende como um objeto de conhecimento determinado sócio-historicamente, fazendo parte dos processos através dos quais os sujeitos se constituem. Ou seja, os instrumentos linguísticos fazem parte da construção histórica das formações sociais, suas instituições, sua ordem cotidiana (ORLANDI, 1998a). Isso porque dizemos de uma posição teórico-epistemológica que compreende que "tratar as ideias linguísticas é tratar a questão da língua, dos instrumentos tecnológicos a ela ligados e da sua relação com a história do povo que a fala" (GUIMARÃES; ORLANDI, 1996, p. 9). Nesse sentido, é produtiva a compreensão de Cervo (2012, p. 17) quando afirma que pensa o museu como "uma forma outra de tecnologização da língua", compreendendo, a partir de Petri (2012), que 
riamente promover um processo outro de gramatização, conforme o conceito proposto por Auroux (1992). Isso significa, para nós, que o museu discursiviza sobre a língua, instrumentalizando-a como objeto de museu pela recuperação do imaginário da língua nacional a partir de um processo já antes historicizado nas e pelas gramáticas e dicionários, pelo saber escolar. Em relação a esse imaginário, o museu pratica uma reinscrição de princípios valorativos que tangem à ressignificação política da

Claudia

Castellanos

Pfeiffer língua por formas outras de nomeação e designação no interior dos espaços reservados ao patrimônio, ressignificação essa que reproduz, tão somente, os sentidos de evidência significados na e pela memória e história dessa língua comum a todos os brasileiros. Por isso, a tecnologização que instrumentaliza, mas não a gramatização da língua no museu. (CERVO, 2012, p. 191).

Concordamos com a autora. O Museu da Língua Portuguesa não permite rupturas no processo de gramatização; pelo contrário, o sustenta na direção que foi tomando ao longo da história de colonização brasileira, que implicou uma colonização linguística (MARIANI, 2004). E insistimos: a diversidade no Museu aparece estruturalmente como variação ou contiguidades estéreis, tal qual vai se constituindo o processo de gramatização brasileiro, que, apesar das contradições entre a historicização e a universalização da(s) língua(s), desemboca na transparência de que a língua portuguesa do Brasil é a língua portuguesa de Portugal: sua variação ou seu mau uso.

Pensamos que esse jogo entre a unidade e a variação que se dá no Museu, que não promove rupturas no processo de gramatização da língua portuguesa no Brasil, funciona tal qual nos coloca Orlandi (1998b), falando a respeito do discurso da globalização:

\footnotetext{
A posição do sujeito é a mesma, apesar do jogo da argumentação na sua variedade porque se trata de diferentes elementos da formulação mas que não mudam nada na posição discursiva do sujeito em sua relação simbólica com a histórica. Não há deslocamentos no nível da constituição para que haja um novo sentido, uma outra posição do sujeito. (ORLANDI, 1998b, p. 80).
}

Feitas essas considerações preliminares que nos situam teórico-epistemologicamente em nossa relação analítica com o Museu da Língua Portuguesa, passemos ao nosso arquivo. 


\section{O discurso institucional do Museu}

Nosso recorte analítico sobre o museu se dará por meio de parte do discurso institucional que o apresenta em sua página eletrônica. É importante lembrarmos que, ao tomar a página institucional do Museu, a estamos compreendendo como um discurso, uma textualização do político que trabalha/é trabalhada o/pelo simbólico e o/pelo político, tal como nos ensina Orlandi (1998b), em sua reflexão produtiva a partir de Pêcheux (1982) e Courtine (1986):

A Análise de Discurso trabalha a textualização do político (J.J. Courtine, 1986) sendo que a apreensão dessa textualização vem Língua em museu de uma análise dos gestos de interpretação inscritos na materialidade do texto. Na medida em que o político é constitutivo, a compreensão, a própria leitura, em Análise de Discurso, é política. Em outras palavras, 'a análise de discurso se confronta com a necessidade de abrir conjuntamente a problemática do simbólico e do político' (M. Pêcheux, 1982). (ORLANDI, 1998b, p. 74).

Ainda, é preciso dizer que estamos tomando o discurso institucional do Museu circunscrito em sua página eletrônica e o próprio $\mathrm{Mu}$ seu enquanto discursos sobre (MARIANI, 1998) constitutivos do processo de institucionalização da língua portuguesa no Brasil.

Quando falamos em processo de institucionalização, estamos pensando nas formas de instituir um discurso como a referência transparente, visível e estável que permite dar sentido a. Pensamos essa construção de instituir, tal como a pensa Mariani (1998, p. 71), enquanto "fruto de longos processos históricos durante os quais ocorre a sedimentação de determinados sentidos concomitantemente à legitimação de práticas e condutas sociais". Nesse sentido, e pensando especificamente em um museu que toma para si a língua portuguesa como seu objeto, é preciso que nos perguntemos sobre as condições de produção (PÊCHEUX, 1975) que sustentam a possibilidade de instituir a língua portuguesa como uma língua/lugar de união (mote do Museu - a língua é o que nos une - já bem trabalhado pelas pesquisas citadas de Cervo, Silva Sobrinho e Romão), a língua portuguesa como a língua nacional, a língua portuguesa como a língua oficial, a língua portuguesa como a língua materna dos brasileiros, a língua portuguesa como "nosso idioma". Processos tensos, contraditórios, em que um equívoco funciona produtivamente: a equivalência des- 
tes atributos (histórico-político-ideológicos) - nacional, materna, oficial - e do pronome possessivo na primeira pessoa do plural fazendo referência a uma mesma língua circunscrita no, também histórico-político-ideológico, atributo portuguesa (PFEIFFER, 2005).

E é justo no espaço do Museu - espaço institucional de um discurso sobre - que esta língua é nomeada, classificada, narrada, entre línguas ditas como variações, estrangeiras, mãe, irmãs...

E, como já indicamos, tomaremos essa narrativa por um lugar Claudia específico: aquele que apresenta, justifica, organiza o Museu publicaCastellanos Pfeiffer mente: sua página eletrônica, que promove um discurso sobre o Museu.

Estamos entendendo o funcionamento do discurso sobre a partir das proposições de Mariani (1998, p. 60-61), que, ao pensar o discurso jornalístico como um tipo de "discurso sobre", compreende-o como discurso intermediário que transita na corelação entre narrar/descrever um acontecimento singular, estabelecendo sua relação com um campo de saberes já reconhecido pelo interlocutor. Nesse sentido, o discurso jornalístico, para a autora, faz parte da institucionalização social dos sentidos, produzindo efeitos na constituição de um imaginário social que permite a cristalização da memória do passado, bem como a projeção de uma memória do futuro. O Museu, como um tipo de espaço de divulgação científica e também de repositório, estaria funcionando nesta mesma ordem discursiva.

A pergunta que nos fica é: que memória é essa que se projeta discursivamente para o futuro? Que memória é essa que não pode ser esquecida? Essas nossas perguntas incidirão em nossa tentativa de analisar o discurso institucional do Museu, que o apresenta e o institui em um lugar público, especializado, fora da escola, mas a ela relacionado, conforme veremos, para se dizer sobre a língua.

\section{O Museu na página ${ }^{2}$}

Começamos nosso movimento entre descrever e interpretar - balizar, para a Análise de Discurso - chamando a atenção para a forma material do endereço eletrônico da página, que promoveria uma desvinculação do Museu a qualquer relação institucional pública: <http://www.museulinguaportuguesa.org.br>.

2 Quando começamos nossas análises, tínhamos por objetivo trabalhar todos os links da página eletrônica do museu, o que se mostrou inviável. Esse objetivo foi redesenhado e será desdobrado em futuras publicações. 
Há aí uma indicação de autonomia que a princípio retiraria o $\mathrm{Mu}$ seu de sua relação com políticas de Estado, com políticas de governo, com políticas públicas. O Museu poderia, facilmente, ser confundido com uma organização não governamental, por exemplo, uma vez que a página não é .gov, mas .org.

Isso não se mantém ao abrirmos a página, repleta de formas materiais que fazem lembrar ao visitante que se trata de uma instituição do Governo do Estado de São Paulo, e, particularmente, com sede na Secretaria de Cultura, como vemos na figura 1 , referente à página de entrada do Museu. É importante notar que, para chegarmos à página do Museu, não é preciso entrarmos na página do governo do estado de São Paulo, mas chegamos à página do governo por links na página do Museu.

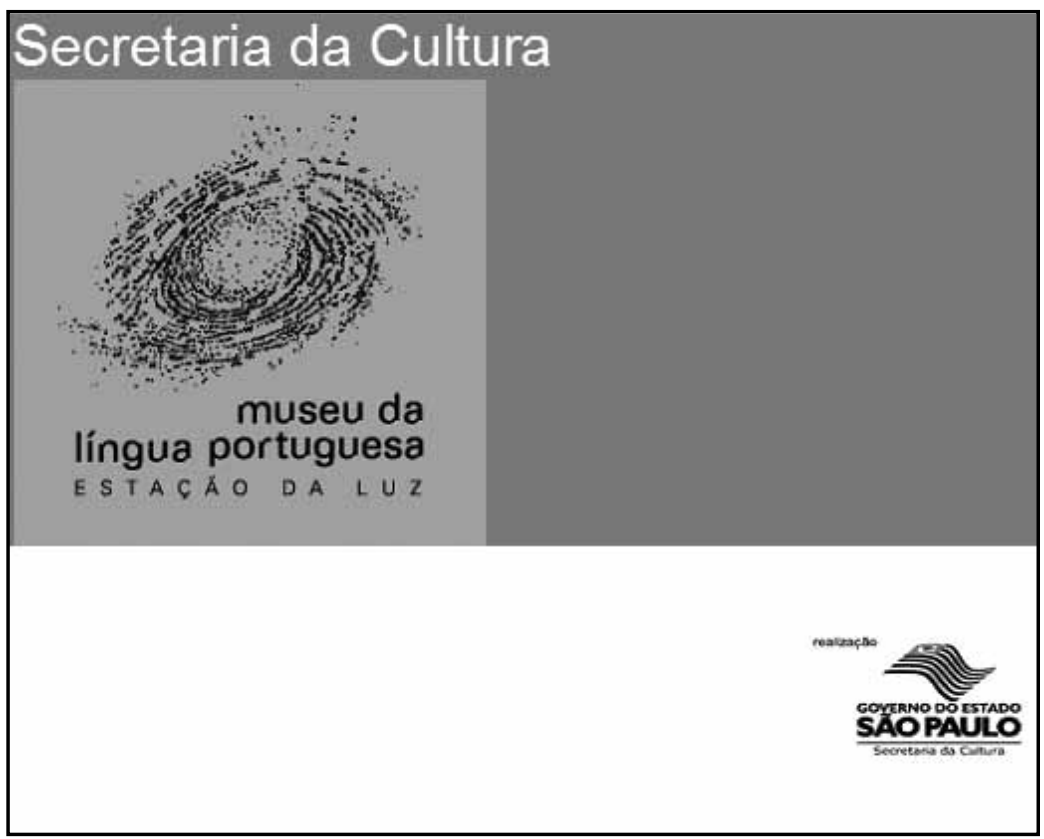

Figura 1 - Página de entrada do museu

Fonte: <http://www.museudalinguaportuguesa.org.br>.

Não faz parte de uma análise discursiva buscar responder por que haveria esta indistinção inicial marcada no Museu. Mas cabe-nos perguntar sobre seus efeitos, que desvinculam, imaginariamente, a língua de uma sua política. O que essa indistinção promove e quais são suas bases de sustentação? De nosso ponto de vista, essa indistinção materializa o apagamento de que a língua é objeto de políticas 
de Estado e de Governo que a administram, que lhe dão uma direção, que afetam o imaginário de seus falantes. Este apagamento sustenta e é sustentado por uma rede discursiva que naturaliza a língua como algo originalmente intrínseco ao indivíduo, hoje fortemente acolhida no argumento do cultural (RODRÍGUEZ-ALCALÁ, 2010), como se a língua trouxesse nela marcas próprias que caracterizassem um indivíduo e um povo.

Nisso nos lembramos de posições muito típicas que circulam Claudia nos arquivos sobre as línguas, como: a língua é um reflexo da índole Castellanos de um povo (PFEIFFER, 2005) (muito própria do século XIX e início Pfeiffer do XX), a língua é a cara de um povo (muito própria de movimentos nacionalistas/fascistas [RODRÍGUEZ-ALCALÁ, 2010]), a língua e suas variações são a expressão de uma cultura multiforme (muito própria de um multiculturalismo que se desdobra nas variações de uma pretensa mesma língua). Esses lugares argumentativos sobre a língua vão apagando o processo de administração/sistematização de uma língua imaginária, que se dá na tripla injunção de um trabalho legislador do Estado, regulador da instrução, e a tradição gramatical (GUIMARÃES; ORLANDI, 2001).

Há, portanto, e sempre houve, um trabalho do Estado sobre a língua que, quase invariavelmente, se dá na relação de sustentação de um conhecimento linguístico alçado ao lugar de assessorar, como conhecimento especializado, o poder público em suas políticas. E isso é apagado na naturalização mesmo da língua, dita como elo ou índice cultural. Evidenciada em sua espontaneidade, como se não houvesse um trabalho sobre ela - tanto aquele trabalho que a administra, que a torna evidente, quanto o trabalho contínuo do sujeito com a língua.

Podemos ainda nos perguntar, olhando internamente para a página eletrônica, sobre o efeito discursivo de sediar o Museu na Secretaria de Cultura. Precisaríamos dar opacidade a esse gesto, que poderia ser tomado na evidência de se tratar de um museu, um equipamento historicamente vinculado à cultura e, muitas vezes, utilizado para fins pedagógicos. Sobra para nós esta brecha: o Museu poderia estar vinculado à Secretaria de Educação? O que vimos compreendendo é que não, não poderia, apesar de se apresentar com um cunho iminentemente pedagógico - sobretudo por seu viés de divulgação científica, como mostra a seção específica que disponibiliza textos de 
especialistas sobre a língua portuguesa ${ }^{3}$. Não pode estar na Secretaria de Educação, apesar também de apresentar uma língua pronta e acabada para ser reconhecida como aquela que deva ser ensinada e consumida (ZOPPI-FONTANA; DINIZ, 2008, ZOPPI-FONTANA, 2009), justo porque seu argumento de existência é um louvar a língua enquanto um patrimônio - não histórico, mas imaterial - que se filia à cultura de um povo, à identidade de um povo.

Voltemos nosso olhar para a logomarca do $\mathrm{Museu}^{4}$ em sua relação com o texto que introduz o Museu em sua página inicial (Figura 2):

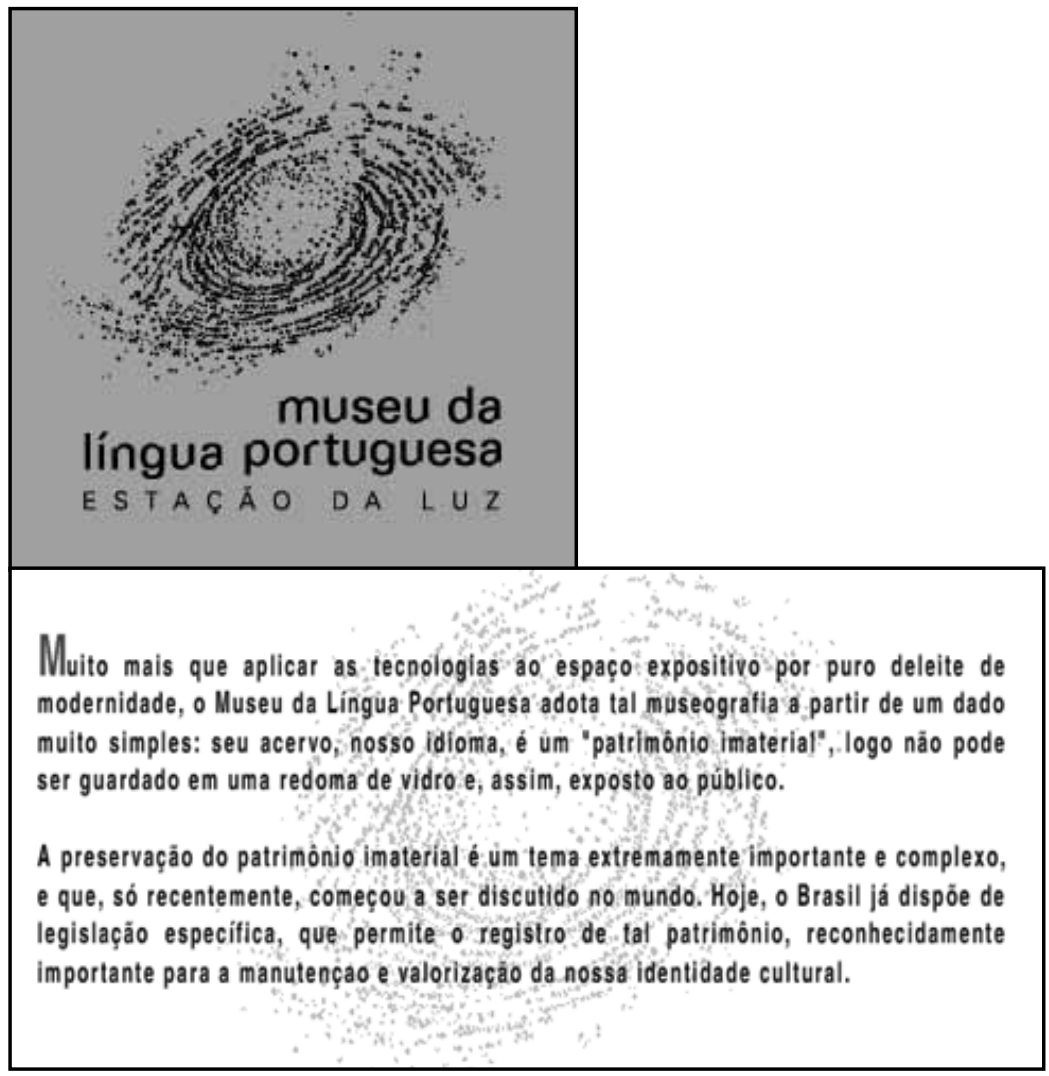

Língua em museu

Figura 2 - Logomarca do museu e texto introdutório da página inicial Fonte: <http://www.museulinguaportuguesa.org.br/>.

3 Disponível em: <http://www.museulinguaportuguesa.org.br/colunas.php>.

4 Também comentado por Silva Sobrinho (2011, p. 72) e por Cervo (2012, p. 120). 
É importante ressaltar que parte da logomarca acompanha, como mancha d'água, o texto de apresentação, produzindo um fundo com a marca de um polegar. Compreendemos essa marca da impressão digital em uma relação dupla: ela transcende o espaço digital que acolhe o Museu e que - pela tecnologia - dá base material para o que é considerado imaterial; e também como uma marca de identificação - lembrando que a impressão digital é única, não se repete de indivíduo para indivíduo. Temos aí a materialização daquilo que é espontâneo e individual, mas Claudia também (por somatória/por metáfora) relativo a um povo: uma identiCastellanos dade cultural construída pelo "nosso idioma", tal como a língua é desig-

Pfeiffer nada nesse texto de abertura. É patente o apagamento da história (do político) nessa relação direta entre língua, patrimônio e cultura, pois o 238 que é imaterial já vem significado na diferença com o histórico (o patrimônio histórico), e aí a língua une todos em torno de uma cultura. o histórico, tomado de uma forma absolutamente cronológica, fica reservado para o prédio que acolhe o Museu - a Estação da Luz - no pé da página eletrônica (Figura 3):

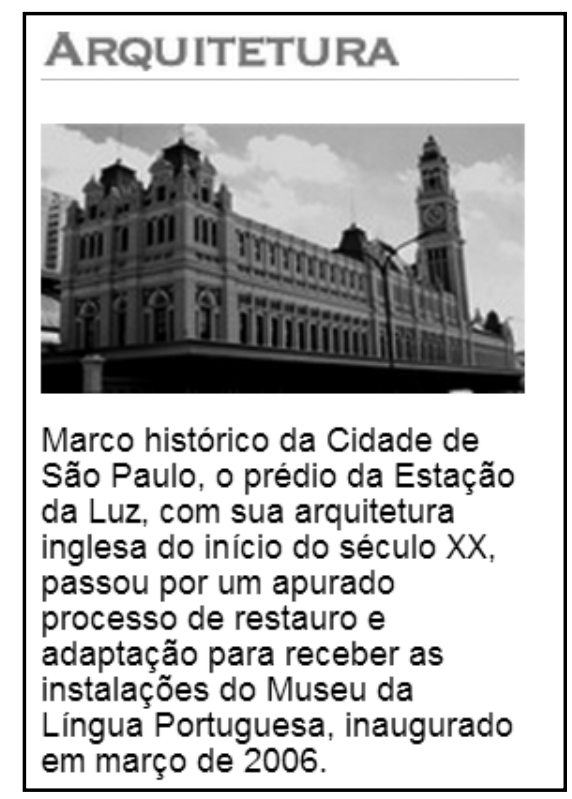

Figura 3 - Breve histórico sobre o prédio que sedia o museu Fonte: <http://www.museudalinguaportuguesa.org.br>. 
Poderíamos nos perguntar ainda sobre os efeitos de sentido da junção entre o "histórico" do prédio material - de arquitetura inglesa - e o "nosso idioma" imaterial, que se desguarda, mas é registrado nesse espaço. 0 que compreendemos é que, nesta trama discursiva que vai sendo construída e que justifica e organiza o museu, as relações entre nações/dominações/colonizações vão se passando sempre de forma muito cordial, dentro de uma linearidade de somatórias de grandiosidades externas ou internas ao país que só vêm a celebrar ainda mais a cultura brasileira com uma rica história de contatos. Apaga-se a historicidade que dá espessura a estes contatos em que as relações de força e de sentido não cessam de se dar.

Língua em

Retornando ao texto de apresentação copiado na figura 2, observamos que idioma e língua também são tomados parafrasticamente. O Museu é da Língua Portuguesa e seu acervo é o nosso idioma. O acervo do museu não é relativo a algo que é de todos, mas apenas ao que cabe em nosso. Quem é o "nós" tão naturalmente trazido à cena de interlocução construída nesse texto de apresentação? O texto se dirige, portanto, àqueles que cabem nesse "nós" constituído nesse idioma que é de um grupo dado como de todos.

É preciso ainda observar que a tecnologia é justificada pela impossibilidade de apreensão (não se pode guardá-lo em uma redoma de vidro) do acervo deste arquivo, deste museu: o "nosso idioma". Nosso idioma é patrimônio e esse patrimônio é imaterial. Se não se guarda, o que se faz com o "nosso idioma", o acervo deste museu? Registra-se. E há uma legislação que permite fazer isso. E é o registro que garante a manutenção e a valorização da nossa identidade cultural. Identidade que se materializa na unidade permitida pela visibilidade de um acervo (in)guardável que o museu traz: a língua portuguesa, apagando a opacidade dessa designação que se apresenta em sua unidade inquebrável pela representação cultural que carrega consigo.

Sobre esse aspecto, é interessante a leitura do documento que cria o Museu, o Decreto nº 50.322, de 8 de dezembro de 2005 (Quadro 1): 


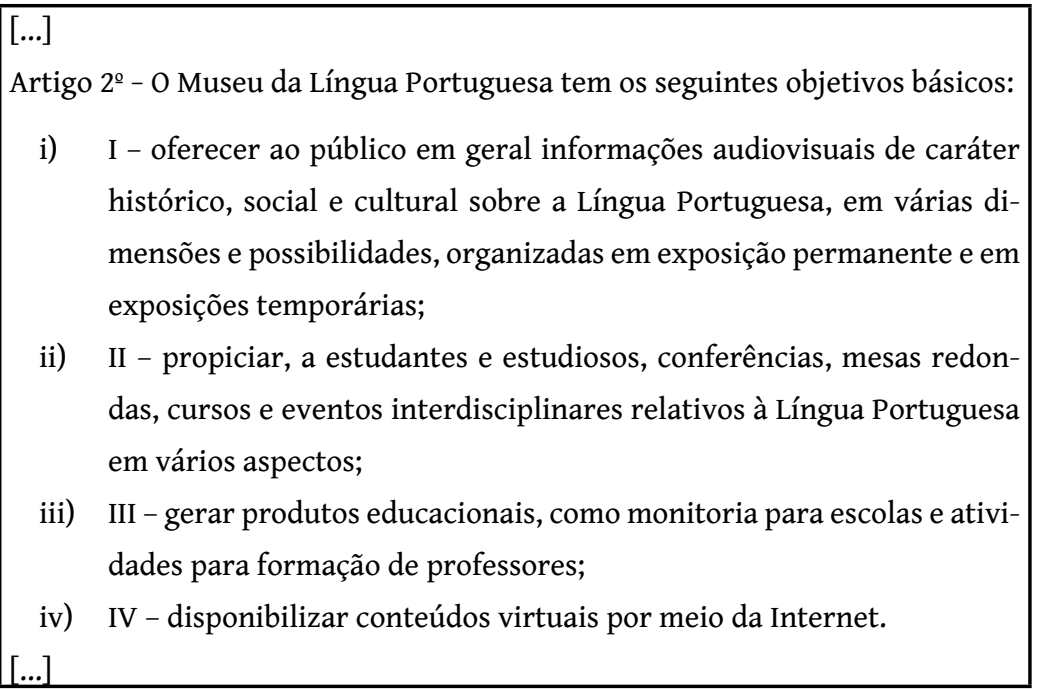

Quadro 1 - Trecho do decreto de criação do museu

Fonte: <http://www.legislacao.sp.gov.br/legislacao/dg280202.nsf/5fb5269ed17b47ab832 56cfb00501469/48717e40f0a28bba032570d20065e3df?OpenDocument>.

Trazendo agora os objetivos presentes na página eletrônica do Museu, no link Institucional, percebemos deslizes de sentido muito interessantes que nos permitem melhor compreender o lugar da cultura no Museu (fazendo-nos compreender melhor a naturalização de seu vínculo à Secretaria de Cultura, por exemplo) (Quadro 2, grifos nossos):

Os principais objetivos do Museu da Língua Portuguesa são:

- mostrar a língua como elemento fundamental e fundador da nossa cultura;

- celebrar e valorizar a Língua Portuguesa, apresentada em suas origens, história e influências sofridas;

- $\quad$ aproximar o cidadão usuário de seu idioma, mostrando que ele é o verdadeiro "proprietário" e agente modificador da Língua Portuguesa;

- valorizar a diversidade da Cultura Brasileira;

- favorecer o intercâmbio entre os diversos países de Língua Portuguesa;

- promover cursos, palestras e seminários sobre a Língua Portuguesa e temas pertinentes;

- realizar exposições temporárias sobre temas relacionadas à Língua Portuguesa e suas diversas áreas de influência.

\section{Quadro 2 - Objetivos do museu}

Fonte: <http://www.museulinguaportuguesa.org.br/institucional.php>. 
O que desliza entre o decreto e os principais objetivos explanados na página institucional do museu? A nosso ver, o principal deslize se dá na mudança de foco entre o decreto e a página: no decreto, fala-se da língua ; na página, fala-se de uma cultura, e a língua está ali para demonstrar essa cultura e valorizar a diversidade cultural brasileira. A língua é fundamental e fundadora da nossa cultura. É por isso que poderíamos compreender que em nosso idioma, acervo do Museu, encontramos já inscrita a deriva, que nos indica o equívoco que sustenta a instauração do Museu: nossa cultura.

No decreto, fala-se a um público em geral; na página, fala-se a um cidadão usuário da língua. No decreto, fala-se sobre o caráter histórico, social e cultural da língua; na página, fala-se de valorizar a língua apreLíngua em museu sentando suas origens, história e influências sofridas. No decreto, nada se fala em termos de uma política de internacionalização da língua; na página, dirigindo-se a um cidadão usuário (relação com o Estado), fala-se também a países falantes de língua portuguesa, por meio do argumento de uma facilitação de intercâmbio (de quê?).

Em meio a esta instabilidade discursiva - a quem se dirige a página; a quem se dirige o Museu; a que se destina o Museu; a que se prestam as exposições? -, vamos compreendendo melhor que o apagamento político do funcionamento da língua no Museu se dá por sua evidência enquanto elemento fundamental e fundador de uma cultura que permanece una no argumento da diversidade cultural tanto quanto a língua permanece una no argumento de sua variação. Nesta instabilidade, há sempre um resto em "nós" que fica apagado, na despolitização das relações entre línguas e sujeitos. E, de nosso ponto de vista, é esse "nós" que não pode ser esquecido pelo acervo, na língua inscrita em nosso idioma, para que o resto se mantenha em seu devido lugar. O Museu cumpre, assim, sua finalidade de celebrar um patrimônio que não pode ser esquecido...

5 Isso não significa que o decreto já não traga em sua textualidade condições de produção para que esse deslize entre língua e cultura se dê. 


\section{Referências}

AUROUX, S. A Revolução tecnológica da gramatização. Campinas: Ed. da Unicamp, 1992.

CERVO, L. M. Língua, patrimônio nosso. 2012.196 f. Tese (Doutorado em Letras)-Universidade Federal de Santa Maria, Santa Maria, 2012.

Claudia GUIMARÃES, E.; ORLANDI, E. Identidade lingüística. In:

Castellanos (Org.). Língua e cidadania: o português no Brasil. Campinas: Pontes, 1996. p. 8-14. Formação de um espaço de produção lingüística: a gramática no Brasil. In: ORLANDI, E. (Org.). História das Idéias Lingüísticas: construção do saber metalingüístico e constituição da língua nacional. Campinas: Pontes; Cáceres: Unemat, 2001.

INDURSKY, F. A análise do discurso e sua inserção no campo das ciências da linguagem. Cadernos do Instituto de Letras da UFRGS, n. 20, dez. 1998.

MARIANI, B. O PCB e a imprensa: os comunistas no imaginário dos jornais (1922-1989). Rio de Janeiro: Revan; Campinas: Ed. da Unicamp, 1998.

. Colonização lingüística; Brasil (séculos XVI a XVIII) e Estados Unidos da América (século XVIII). Campinas: Pontes, 2004.

ORLANDI, E. P. (Org.). Política lingüística na América Latina. Campinas: Pontes, 1992.

Ética e política lingüística. Línguas e Instrumentos Lingüísticos, Campinas: Pontes, n. 1, 1998a.

Discurso e argumentação: um observatório do político. Fórum Lingüístico, Florianápolis, n. 1, p. 73-81, jul./dez. 1998 b.

. (Org.). História das idéias lingüísticas: construção do saber 
metalingüístico e constituição da língua nacional. Campinas: Pontes; Cárceres: Unemat, 2001.

ORLANDI, E. P. Espaços linguísticos e seus desafios: convergências e divergências. RUA [online], n. 18, v. 2, nov. 2012.

PÊCHEUX, M. A. Análise de Discurso: três épocas (1983). In: GADET, F.; HACK, T. (Org.). Por uma análise automática do discurso: uma introdução à obra de Michel Pêcheux. Campinas: Ed. da Unicamp, 1997. p. 311-319.

Língua em museu . Les vérités de la Palice. Paris: Maspero, 1975.

PÊCHEUX, M. (Thomas Herbert). Reflexions sur la situation théorique des sciences sociales et, spécialement, de la psychologie sociale. Cahiers pour l'analyse, 2, p. 174-203, 1966.

PETRI, V. Gramatização das línguas e instrumentos linguísticos: a especificidade do dicionário regionalista. Língua e instrumentos lingüísticos, Campinas: RG Editora, n. 29, p. 23-37, jan./jun. 2012.

PFEIFFER, C. O saber escolarizado como espaço de institucionalização da língua. In: GUIMARÃES, E.; BRUM-DE-PAULA, M. R. (Org.). Sentido e memória. Campinas: Pontes, 2005. p. 27-40.

RODRÍGUEZ-ALCALÁ. Políticas públicas de direito à língua e consenso etnocultural: uma reflexão crítica. In: ORLANDI, E. P. (Org.). Discurso e políticas públicas urbanas: a fabricação do consenso. Campinas: RG Editora, 2010. p. 127-160.

ROMÃO, L. M. S. Exposições do Museu da Língua Portuguesa: arquivo e acontecimento $\mathrm{e}(\mathrm{m})$ discurso. São Carlos: Pedro \& João Editores, 2011.

SILVA SOBRINHO, J. S. Os nomes da língua do Brasil no Museu da Língua Portuguesa: uma questão política. Sínteses (Unicamp Online), v. 14, p. 386-404, 2009. 
SILVA-SOBRINHO. J. S. “A língua é o que nos une": língua, sujeito e Estado no Museu da Língua Portuguesa. 2011. 133 f. Tese (Doutorado em Linguística)-Universidade Estadual de Campinas, Campinas, 2011.

ZOPPI-FONTANA, M. G (Org.). o português do Brasil como língua transnacional. Campinas: RG Editora, 2009.

; DINIZ, L. R. A. Declinando a língua pelas injunções do mercado: Claudia institucionalização do português língua estrangeira (ple). Estudos Castellanos Lingüísticos, São Paulo, v. 37, p. 89-119, 2008.

Pfeiffer 